\title{
An empirical study of supply chain sustainability with financial performances of Indian firms
}

\author{
Nikunj Sachin ${ }^{1} \cdot$ R. Rajesh ${ }^{1}$ (D) \\ Received: 25 May 2020 / Accepted: 30 July 2021 / Published online: 9 August 2021 \\ (c) The Author(s), under exclusive licence to Springer Nature B.V. 2021
}

\begin{abstract}
In this research, we examine empirically the impact of sustainable supply chain practices on financial performances, considering the case of Indian firms. Here, we use a sample of 25 Indian firms listed for their sustainability performances in the Thomson Reuters Environmental, Social and Governance (ESG) scores. The sustainability performance data have been accessed from the Bloomberg terminal, where the overall sustainability performance on ESG is measured as a discounted score on ESG considering various controversies on ESG reported for the firm. And for the study, we associate financial data using the profit indicators of firms. We perceive that the sustainable supply chain practices considering environmental, social and governance performances may not positively impact the financial performance measured by the Return on Asset (ROA) and Return on Equity (ROE), during the considered period of five years for the study. We construct the empirical model and use Partial Least Square (PLS) regression modeling to analyze the results. The study can be further extended for many Indian firms and for firms across different developing economies, as well. The major implications of this research are to observe for firms and their supply chains whether the implementation of Environmental, Social and Governance (ESG) practices can help them in achieving financial benefits, along with other competitive advantages. The research is built on the concept and theory of ecological modernization, which suggests for the economic benefits of environmentalism.
\end{abstract}

Keywords ESG scores · Sustainability performances · Corporate social responsibility · Financial performances $\cdot$ Empirical study

R. Rajesh

rajeshambzha@gmail.com; rajesh@iiitm.ac.in

Nikunj Sachin

sachinnikunj@gmail.com

1 Management Division, ABV-Indian Institute of Information Technology and Management (ABVIIITM), Gwalior, India 


\section{Introduction}

In the present era, we witness that contemporary firms are highly competitive considering their industrial sector. And their supply chains have impacted a lot on the industrial sector mainly to improve the services of firms, along with creating the awareness for environmental, social, and governance dimensions in sustainability to promote their businesses. However, there are lots of issues considering environmental performances such as; deforestation, carbon emissions and footprint, pollution of the air, water, and soil resources, excessive use of non-renewable resources, social issues like workers health, safety and security, violation of labor acts and governmental regulations, social risk management, partner relationships considering societal impacts, education, and welfare measures. (Jamali \& Karam, 2018). These issues can raise concerns regarding environmental, social, and governance performances and innovative solutions are needed to reduce these impacts. Green manufacturing is one solution to aid the supply chain to improve green performances, but it takes care only of the environmental factors, as we see from the literature (Gandhi et al., 2018). Also, we can observe from the literature that there are increasing considerations for sustainability and related issues in the supply chain context allowing for the present COVID-19 crisis (Chowdhury et al., 2021).

The organization can avoid or mitigate these issues to keep track of their supply chains toward creating resilient and sustainable supply chain (SSCM) for future (Lins et al., 2017; Rajesh et al., 2021). Many firms have ongoing SSCM practices in India; however, researches in the direction to investigate the financial performances of firms and its' association with sustainability in supply chains is lacking in the literature, particularly in the developing country context. This paper examines the sustainable supply chain interventions that can benefit the environmental, social and governance performance and can simultaneously improve the operational and financial performance of firms. The purpose of this study is to investigate the financial performance of firms, where SSCM practices have been well implemented. We hypothesize that companies already adopted SSCM practices have significant positive impacts on their financial performances. We consider in this study, a sample of 25 leading firms that have adopted SSCM practices, successfully. To investigate this, we extract the secondary data of Environmental, Social and Governance (ESG) scores from a database of Thomson Reuters using Bloomberg terminal. We further investigate the direct relations that can influence the SSCM practices of Indian firms and to achieving financial performances. Through the measures of ROA (Return on Asset), ROE (Return on Equity), we relate the sustainability performances of firms with financial performances.

\subsection{Sustainable supply chain management}

Sustainable Supply chain management (SSCM) involves all the activities leading to reduce the carbon footprints of products and to improve the ecological, environmental, and social well-being. Sustainability as a concept has been adopted in supply chains, later evolved into the theory and practice of sustainable supply chains (Dubey et al., 2017). Ecological modernization theory is one of them stating the monetary benefits for considering the ecological considerations. Although sustainable supply chain management was initiated in a direction to addressing the environmental and social issues, it can give significant benefits for the firm on a long run (Mathivathanan et al., 2017). Several studies (Lee \& Schniederjans, 2017; Narimissa et al., 2020a, 2020b; Rajesh, 2021) confirm that sustainable 
supply chains have significant benefits considering competitive advantages and for having a greener image for future. The impacts of sustainable supply chain practices on the financial performances of firms were also explored in the context of several developed economies (Hong et al., 2018; Yusuf et al., 2019).

\subsection{Financial performances}

Several studies have discussed on the financial success of firms in a number of ways. The metrics used to assess SSCM's financial performance can fall into three categories as, lower costs, higher revenues, and increased stock prices. Several researches have looked at operating efficiencies, higher overall cost efficiencies, and risk control at reduced costs (Gopal \& Thakkar, 2016; Miroshnychenko et al., 2017). Also we observe from the literature that some studies have looked at higher sales, higher profitability, price premiums, new business entry, and social license to function under increased revenues, etc. Studies in the direction that sustainability initiatives leading to financial benefits are also seen in the literature (Esfahbodi et al., 2016; Feng et al., 2018). Most of these works in sustainability are in the context of developed economies. Although some literature can be found linking sustainability and financial performances in the context of developing economies, an in-depth study linking the economic, social, and governance performances and financial performances are not seen in the literature.

\subsection{Motivation for the study}

ESG scores and sustainability reporting practices are gaining increased attention in recent times. As we see, many organizations are seen manipulating the system just to avoid reporting several non-sustainable practices. This manipulating of practices will lead to cause a great damage to the environment, as well as the social life of people. The resources on this planet are limited and it is already alarming time to save them and the present generation will have to use resources in a sustainable manner for the existence and arrival of future generations. As we see in the Indian context, the resources are scarce and people are not getting sufficient supply to even fulfill their basic needs. This is high time is to move toward sustainable supply chain management for the benefit of people and the environment. If there are financial benefits associated with moving toward sustainability, then more firms will adopt sustainable supply chain practices. This paper is motivated from the scarce literature on observing the relation binding environmental, social, and governance performances and the financial performances of firms (Tseng et al., 2019; Wolf, 2014).

\subsection{Gap analysis}

There are several researches conducted that analyze the sustainability of supply chains, but in case of India there are limited researches available that consider the sustainability performances and financial data of firms. Hence, we analyze the impact of implementing sustainable supply chain management practices considering the environmental, social, and governance indicators on the financial performance of firms in the Indian perspective. The governance side of performance indicators in sustainability has not been considered in most of the researchers conducted on studying sustainability impacts over financial performances. Also, the impacts of any controversies in ESG over the financial performances of 
firms are not studied in detail. Many researchers have considered the internal factors that influences the financial performance (Wang, \& Sarkis, 2017), while many other researchers have considered only the economic dimension of sustainability and firm performances. Hence, we consider the internal as well as external factors to find the relationship between SSCM practices, based on ESG and financial performance considering the profitability of firms.

\subsection{Objectives of the study}

This research has three major objectives shown as follows.

- To investigate the sustainable supply chain practices and ESG scores of firms in the Indian context.

- To examine, if the firm performance in the environmental, social and governance side can positively affect its financial performances in the Indian context.

- To investigate whether any controversies on ESG can negatively affect the financial performance of firms in the Indian context.

We analyze the connection between ESG ratings and firm performances, where firm performance includes both accounting and market results, and where profitability is defined through ratios of ROI and ROE. The remainder of the paper is organized as follows. Section 2 includes the detailed literature review on sustainability performances, which is followed by the proposed empirical model and hypothesis development in Sect. 3. Section 4 confers the methodology for analysis, which is followed by the results of the PLS analysis and the related discussions in Sect. 5. Section 6 elaborates the conclusions of the study, limitations and scope for further studies. Section 7 includes the implications of the study.

\section{Literature review}

Particularly in the last two decades, the debatable topic is the social and environmental practices in companies and how it can play a significant role in increasing the brand image of company and the value base in management and business ethics. The concept of environmental and social responsibility has been perceived by firms in various manners (Narimissa et al., 2020a, 2020b). Social responsibility implies that organizations, not withstanding, expanding investor esteem, must act in a way that benefits society. Social duty has been progressively critical to speculators and purchasers who look for ventures that are gainful, as well as value adding considering the benefits to society and the environment. As we know in the fundamental idea of any business, society is not being considered as a partner. Hence, the need of social responsibility must be inculcated into business philosophies. Social responsibility, as it applies to business, is referred to as corporate social responsibility (CSR).

Quite a few researchers have dissected the effect of corporate dependable practices and non-monetary data on business execution and have observed non-unique results. Several studies prove that there are significant positive impacts of environmental sustainability practices on financial performance variables (Ortas et al., 2014). Wang and Sarkis (2017) investigated 500 large United States companies to examine the linkages among environmental, social, and financial performance and found a significant positive relationship of 
environmental considerations over financial performances. Tchaikovsky (2017) also found a significant positive relationship between environmental sustainability practices and financial performances of US-based firms. Jayaram et al. (2008) examined several firms that integrate sustainable supply chain practices and observed the relations to the performance of the company.

Sybertz (2017) concluded that SSCM approaches involving environmental, social, and economic output can have a positive relation to firm performance. As per him, it is oversimplifying to comment that; embedding sustainability in a supply chain and seeking to optimize value for all those in the chain would bring financial benefits for all. Büyüközkan and Berkol (2011) analyzed the parameters of economic, social, environment performances of firms though Quality Function Deployment (QFD) model and House of Quality (HOQ) models. Balaji (2010) and analyzed the data of Small and Medium Enterprises (SMEs) in India and studied on the relations binding bankruptcy of firms and their sustainability performances. Garg (2015) examined several practices of chosen organizations in India and analyzed 20 firms in the manufacturing sector performing CSR activities and studied of the impacts of the same on performance of firms.

Balatbat (2012) explained the effect of ESG scores on financial performance of firms that are listed in Australian Securities Exchange and showed that ESG scores are weak positively related to financial performance of firms in the Australian context. Hence, considering the extant literature in this direction, it is observed that the sustainable supply chain practices and the ESG performances of firms may have a positive impact on the financial performances of firms. We observe the same as a pilot study in the Indian context considering the data of 25 firms. A detailed literature on recent works related to sustainability performances of firms and linking the same with their financial performances are shown in Table 1.

We have utilized the ecological modernization theory as the base for proposing relationship between sustainability performances measured on ESG performances and linking the same with financial performances of the firm. Ecological modernization theory points on the economic benefits of environmentalism (Mol \& Spaargaren, 2000). The theory focuses on the environmental re-adaptation of economic growth and industrial development. Hence, the theory suggests that the economy and ecology can be favorably combined for the productive use of natural resources and the environmental media to enhance the labor productivity and capital productivity. Based on the theory, we assume that there is a positive relationship between the sustainability performances of firms and their financial performances. The ESG indicators that are taken for consideration in this study are detailed as follows. These indicators are provided by Thomson Reuters in their sustainability performance evaluation, based on the performances of firms in environmental, social, and governance indicators.

\subsection{ESG scores}

Environmental, Social, and Governance (ESG) scores provided by Thomson Reuters can depict the sustainability performance assessment of firms, and provide directions for improvement in this area (Thomson Reuters ESG Scores, 2019). Environmental gauges to measure environmental impacts of firms can act as a nature steward. Social gauges can measure how firms can handle relations with staff, merchants, purchasers, and understand the social hierarchy, where it works. Governance gauges can indicate the level of authority of a corporation, executive compensation, reviews, inner controls, and investor rights. 


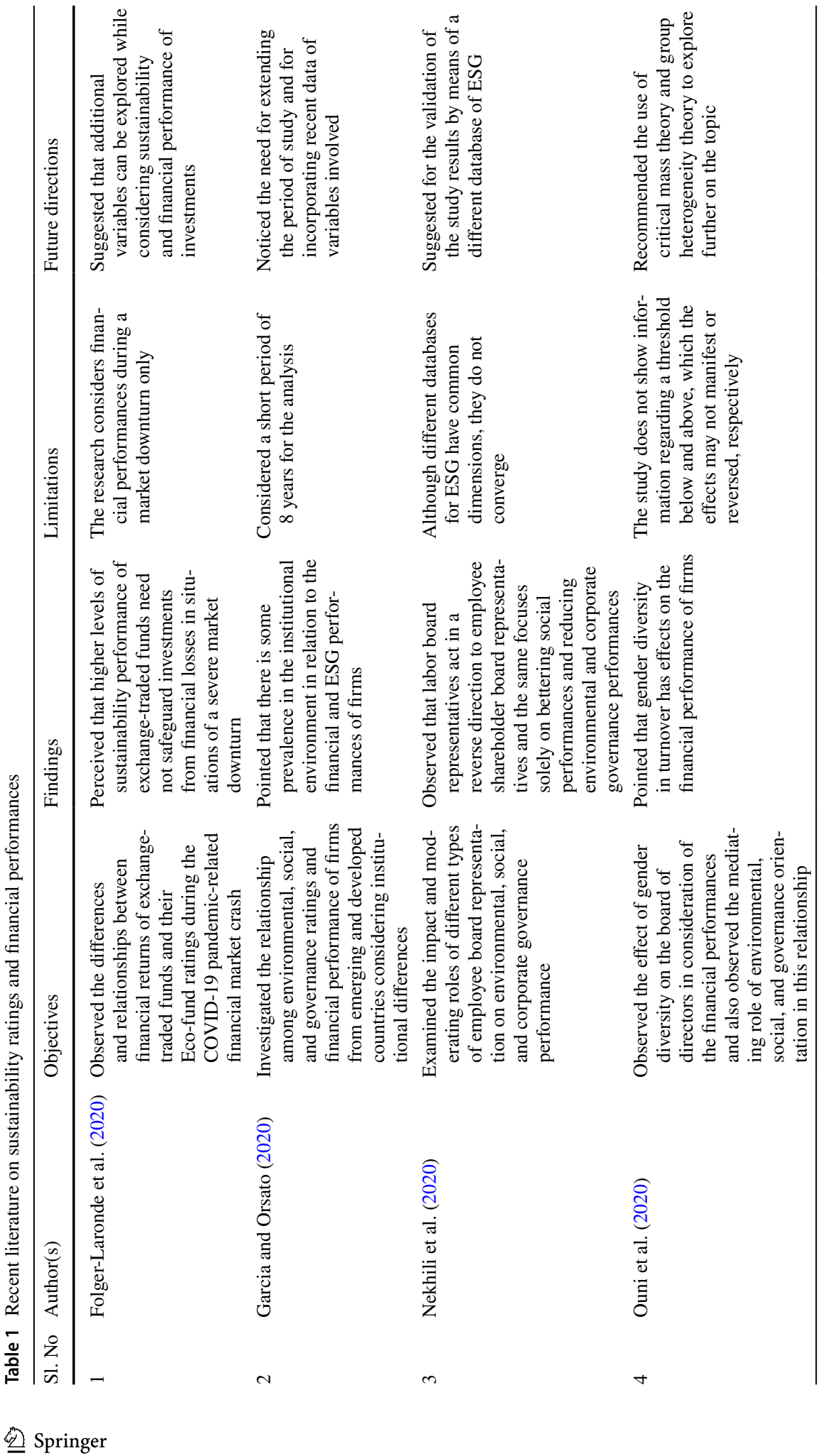




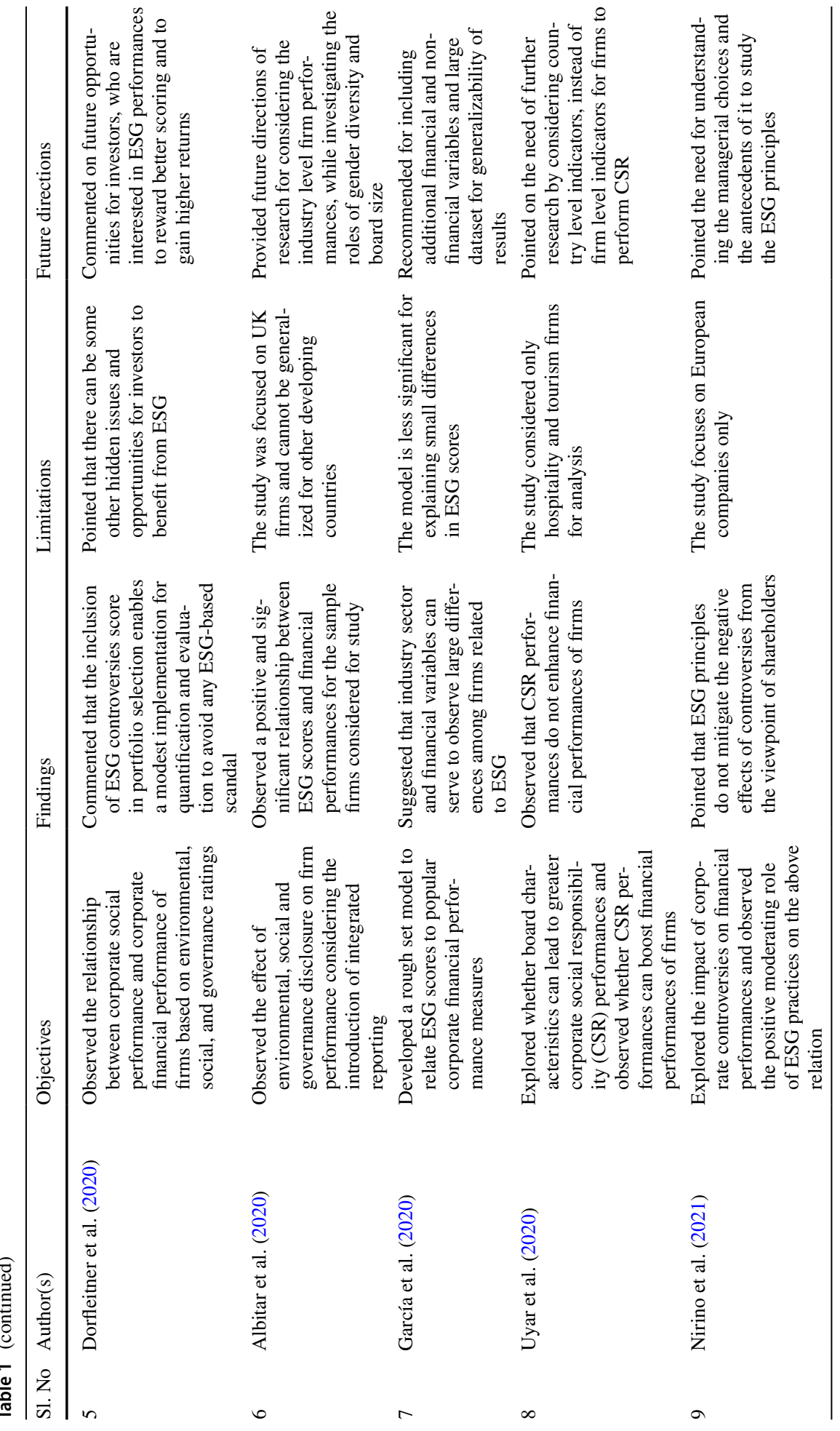




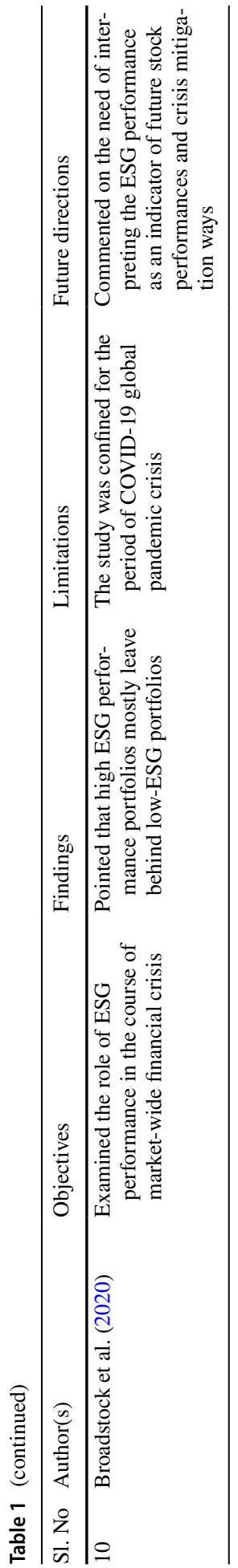

Springer 
Several studies confirm that the ESG scores can act as indicators of the sustainability performances of firms, although the economic dimensions of sustainability are not considered, as such in the measurement scheme.

\subsection{ESG combined score}

The ESG combined scores provide an idea of the adjusted and definite positioning of the ESG yield of a firm, based on the indicators in the ESG columns with an overlay of ESG controversies assembled from worldwide news sources (Thomson Reuters ESG Scores, 2019). This score is designed to limit the ESG scores, considering the negative reports from media. The evaluations are done by incorporating this into the general ESG score, the impact of major and minor ESG controversies on emissions, labor controversies or any product or brand controversies. When the firm has not been put under the limelight of any such debates or controversies, then this discounted ESG score is equal to ESG combined score (Tamayo-Torres et al., 2019).

\subsection{ESG controversies score}

During a particular financial year considered for the study, if the firm has been involved in any type of scandals, or the firms have to pay any kind of penalties that affects organization's reputation, then ESG controversies scores are generated (Thomson Reuters ESG Scores, 2019). The ESG controversies score will be deducted from the total ESG to obtain the discounted measure of ESG, called as the ESG combined scores. If the firms have seen the new developments related to negative events like disputes, fines, lawsuits etc., ESG controversies scores are generated and the same is calculated based on 23 of the latest ESG controversies topics, as calculated by Thomson Reuters.

\section{Hypothesis development}

\subsection{Proposed model}

The empirical model developed for the study is shown in Fig. 1. This model measures the impacts in financial performance due to attaining the sustainable supply chain practices. Based on the empirical model, we develop the research hypothesis for the study.

\subsection{Economic, social, and governance indicators and the ESG scores}

Environmental sustainability of firms and their supply chains are evaluated based on different sub-parameters in ESG, such as the ownership of polluted property, disposal of hazardous waste, control of radioactive emissions, or compliance with environmental regulations of the Government etc. The firm's businesses relationship is considered as a long-term objective. So, it creates social responsibility to all the stakeholders. The political commitment is also significant in supply chains, as firms keep away from irreconcilable circumstances, when enrolling board individuals, do not utilize political commitments to get unduly great treatment and, perceptibly, do not take part in untrustworthy exercises. These 


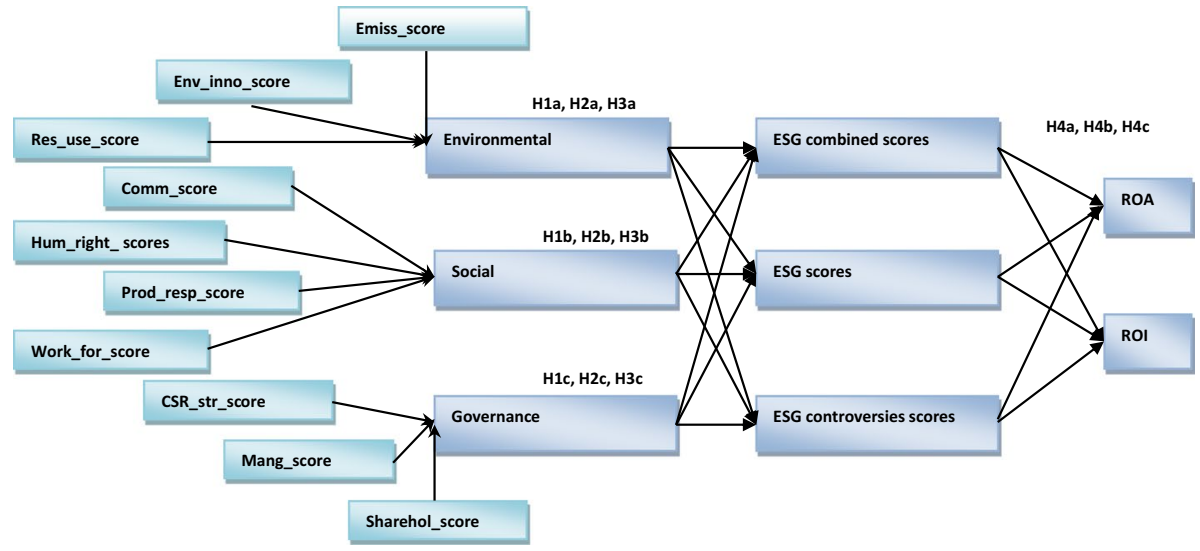

Fig. 1 Proposed model

practices can perk up the ESG score and legitimately sway on corporate money related outcomes in India.

\subsubsection{Environmental factors and ESG score}

Environmental supply chain practices and green initiatives can directly contribute to the firms' ESG score and there are assumed positively effects on the performances of firms in the Indian context. Several researches on environmental sustainable practices examine the impact of ESG on public and organizations' economic performance (Albitar et al., 2020). And many researchers concluded the positive effects of environmental performances on firm performances and in some cases direct relationships were not found.

\subsubsection{Social factors and ESG score}

Social sustainability indicators also have a direct relation over overall ESG performances of firms. Researches in sustainable supply chains have particularly considered social sustainability and examined its focus on human values and concerns. In a broader sense, social concepts include public health, health and safety, local community issues, stockholder issues etc. (Uyar et al., 2020). Moreover, some researches in this direction have shown positive impacts of social factors on overall ESG performances and firm performances, although direct researches in this direction are limited.

\subsubsection{Governance factors and ESG score}

Positive governance measures can directly impact the performance of firms (Albitar et al., 2020). And from several past studies, ESG scores have been found positively related to organizational efficiency. A positive relation can exist among the governance performances and the firm performances in the Indian context. We observe this relation through establishing the empirical model. No formal governance is needed, when the potential conflicts of interests are minimal and the potential conflicts of interests increases, when the number 
of customer groups and services increases. Based on the above, the following hypotheses are formulated.

Hypothesis 1a: Environmental factors can positively and significantly impact ESG scores.

Hypothesis 1b: Social factors can positively and significantly impact ESG scores.

Hypothesis 1c: Governance factors can positively and significantly impact ESG scores.

\subsection{Economic, social, and governance indicators and ESG combined scores}

As we discussed earlier, ESG controversies scores can negatively impact on the sustainability performances of firms (Dorfleitner et al., 2020). This measure of sustainability is dependent on the discounted ESG data of ESG controversies with the ESG discussions overlay caught from worldwide media sources. These discussions and media coverage can badly impact the firm's image and it tarnishes the CSR activities entertained by the firm. We observe similar relations, as discussed in the previous section that environmental, social, and governance scores, separately can have positive and significant impact on the ESG combined scores, which are discounted for ESG controversies. Similarly, we also observe that environmental, social, and governance scores, separately can have negative and significant impact on the ESG controversies scores. The following hypotheses are formed based on the above discussions.

Hypothesis 2a: Environmental factors can positively and significantly impact ESG combined scores.

Hypothesis 2b: Social factors can positively and significantly impact ESG combined scores.

Hypothesis 2c: Governance factors can positively and significantly impact ESG combined scores.

Hypothesis 3a: Environmental factors can negatively and significantly impact ESG controversies scores.

Hypothesis 3b: Social factors can negatively and significantly impact ESG controversies scores.

Hypothesis 3c: Governance factors can negatively and significantly impact ESG controversies scores.

\subsection{ESG scores and financial performances}

There can be a positive connection between the actual ESG score and the financial performance indicators of the firm, such as Return on Assets (ROA) and Return on Equity (ROE). ROA is an indicator representing how profitable a company is relative to its total assets. ROA provides a manager, investor, or analyst an idea to how efficiently the firm can 
be managed using its assets to generate earnings. ROA is displayed as a percentage. ROE is calculated as a measure of the financial performance and is calculated by dividing net income by shareholders' equity. As shareholders' equity is equal to a firm's assets minus its debt, ROE is considered as the return on net assets. ROE is considered as a measure of how effectively management can use company's assets to create profits. Similarly, the ESG combined scores can have a positive influence the financial performance measures, such as the ROA and ROE (Garcia \& Orsato, 2020). And the ESG controversies scores can have a negative influence over the financial performance indicators of the firm, such as the ROA and ROE. Based on the foregoing discussions the following hypotheses are formulated.

Hypothesis 4a: ESG scores can positively and significantly impact on ROA or ROE.

Hypothesis 4b: ESG combined scores can positively and significantly impact on ROA or ROE.

Hypothesis 4c: ESG controversies scores can negatively and significantly impact on ROA or ROE.

\section{Methodology}

Structural equation modeling (SEM) techniques are widely employed in many empirical studies involving primary and secondary data (Rajesh, 2020). This section covers and explains the partial least squares (PLS) approach used to obtain necessary results and to achieve research objectives. PLS is selected in this research, as it has some advantages over regression such as; it can robustly handle more descriptor variables than compounds. Also, it can handle non-orthogonal descriptors and multiple natal results (Cramer, 1993). The predictive accuracy is high and there is a much lower risk of chance correlation. Even then, there are some limitations such as; higher risk of overlooking actual correlations and sensitivity toward relative scaling of the descriptor variables.

\subsection{Sample selection}

To evaluate and investigate the relation binding SSCM practices with financial performances of Indian firms, we have chosen 25 Indian firms that are consecutively rated for their sustainability performances by the ESG ratings of Thomson Reuters and the data being collected from the Bloomberg terminal. About 54 firms appear to be continuously rated for their sustainability performances in the past 5 years, considering the Indian context (Thomson Reuters ESG Scores, 2019). We have done a sorting of these firms and selected well-established firms considering the market potential and narrowed down the number of firms under consideration to 25 . We observe the information about corporate natural management, corporate administration, and divulgence for selecting the 25 established firms in the Indian context. The data of these companies were used to investigate the sustainable supply chain practices through ESG ratings and to examine the financial performances in terms of ROA or ROE. These 25 firms are indicative to study the relationship between sustainable supply chain and financial performance and the study need to be extended for more firms to make vast generalizations in the Indian context or in the context of other developing economies. 


\subsection{Environmental, social, and governance data}

Thomson Reuters' Environmental, Social and Governance scores (ESG) are the main source for this empirical analysis. ESG reports have also considered numerous internal social environment and governance management rankings, as well as external programs such as the socially responsible supply chain management, environmental supply chain management programs. The ESG report of firms can offer full reports on the performance on corporate ESG and sustainability management. Environmental responses to supply chain management can demonstrate a company's attempt to minimize any reckless environmental actions within the supply chain. For instance, it can be observed to study how an organization can limit the material waste in its fabricating process, or permit providers to actualize progressed natural administration frameworks.

On the other hand, social responses in supply chain management allow us to understand how much a firm or its supply chain underpins human rights and prosperity of laborers and welfare of society, considering the supply network. Adding to it, the green supply chain management initiatives can cover several areas of illegal practices harming the environment and conflicts of interest that the firm should avoid. The rating scores on governance performances can thus provide insights to distinguishing firms that are solely focused on internal sustainability management or externally applicable businesses and those firms, who are focused on both internal and external sustainable supply chain management initiatives.

\subsection{Financial performance data}

We observe the information on corporate financial reports from the annual financial statements (e.g., total assets, profit after tax, net debt, and sales before extraordinary items). Specifically, we measure ROA using the formula of profit before extraordinary objects divided by total assets to determining company's efficiency for using its investments to generate earnings. We also measure ROE and it can be observed that ROE ratios can vary considerably from high to low considering industry group and type of industries.

\subsection{PLS regression model}

The multiple linear regression (MLR) models have been applied for testing the empirical relations binding ESG data and financial performances. Here, we observe the data of 25 Indian firms who practice sustainability in their supply chain activities. Structural equation modeling (SEM) techniques can be employed for the empirical study and we use the partial least square (PLS) regression analysis of 25 Indian firms. All of these firms have practiced the SSCM initiatives during a considered period of 5 years from 2014-2018 for the study. PLS is done in a way to examine the constructs and the latent variables contributing to ESG performances and we observe those subsequent influences over financial performances.

\section{Results and discussion}

All SEM analyses were conducted using smart PLS 3 software and we use the partial least square analysis to find the result. The detailed results and discussion of findings are elaborated as follows. 


\subsection{Descriptive statistics}

In this study, we observe the data of 25 Indian firms from the Thomson Reuters ESG and the information is extracted from the Bloomberg terminal. All of these firms were performing sustainability practices in their supply chains. The major variables considered and the basic descriptive statistics for the study are elaborated in Table 2. As from the data, we see that 25 sample firms considered for the study has a mean value for ROA as 1.18 , a mean value for ROE as 2.85. Our sample has different mean values for different ESG measures as; for ESG score, the mean value is 58.26; for ESG combined score, the mean value is 48.07; and for ESG controversies score, the mean value is 42.84. The descriptive statistics summarizes that the ESG scores are found to be increasing in subsequent years and ESG controversies show gradual decreases.

\subsection{Correlation analysis}

The matrix of correlation among items is shown in Table 3. We observe a positive correlation among the environmental, social, and governance scores, and the ESG scores, separately and the same is true for ESG combined scores. Also there is a negative correlation among these factors and the ESG controversies scores of firms.

\subsection{PLS path analysis}

In this study, we investigate and the relationship among sustainability indicators of firms and the financial performances using path analysis in PLS. We have used the smart PLS 3 software and analyzed the impacts of ESG score, ESG combined score, and ESG controversies score on financial performances of firms. The results of multivariate tests using

Table 2 Descriptive Statistics

\begin{tabular}{lccccc}
\hline Scores & N & Minimum & Maximum & Mean & Std. deviation \\
\hline ESG & 125 & 25.5617647 & 85.8224508 & 58.265848949 & 14.9517397753 \\
Resource & 125 & 14.5390071 & 99.1749175 & 62.908585263 & 21.8945703345 \\
Emissions & 125 & 4.9450549 & 99.5192308 & 63.369013642 & 26.1182946967 \\
Environmental Innovation & 125 & 0.2673797 & 99.6721312 & 49.340285379 & 33.8257557857 \\
Workforce & 125 & 5.1020408 & 99.5049505 & 57.148833684 & 23.2345642723 \\
Human Rights & 125 & 16.2721894 & 99.0291262 & 63.134537471 & 27.6675940311 \\
Community & 125 & 18.0769231 & 99.6183206 & 63.695823124 & 26.4144470632 \\
Product Responsibility & 125 & 5.4945055 & 99.6721312 & 59.465358413 & 28.2480656332 \\
Management & 125 & 6.2500000 & 99.5192308 & 54.786619906 & 25.1592868520 \\
Shareholders & 125 & 0.5555556 & 99.5098039 & 57.352850490 & 30.3110727110 \\
CSR Strategy & 125 & 0.9615385 & 99.4047619 & 58.820571337 & 27.3369246822 \\
ESG Combined & 125 & 23.003795 & 80.066592 & 48.07402518 & 13.549429319 \\
ESG Controversies & 125 & 2.1428571 & 71.4285714 & 42.840775485 & 24.2213846562 \\
ROA & 125 & 0.060444 & 2.975184 & 1.18020342 & 0.670518185 \\
ROE & 125 & 0.149351 & 14.633205 & 2.85318138 & 2.495452000 \\
Valid N (list wise) & 125 & & & & \\
\hline & & & & & \\
\hline
\end{tabular}




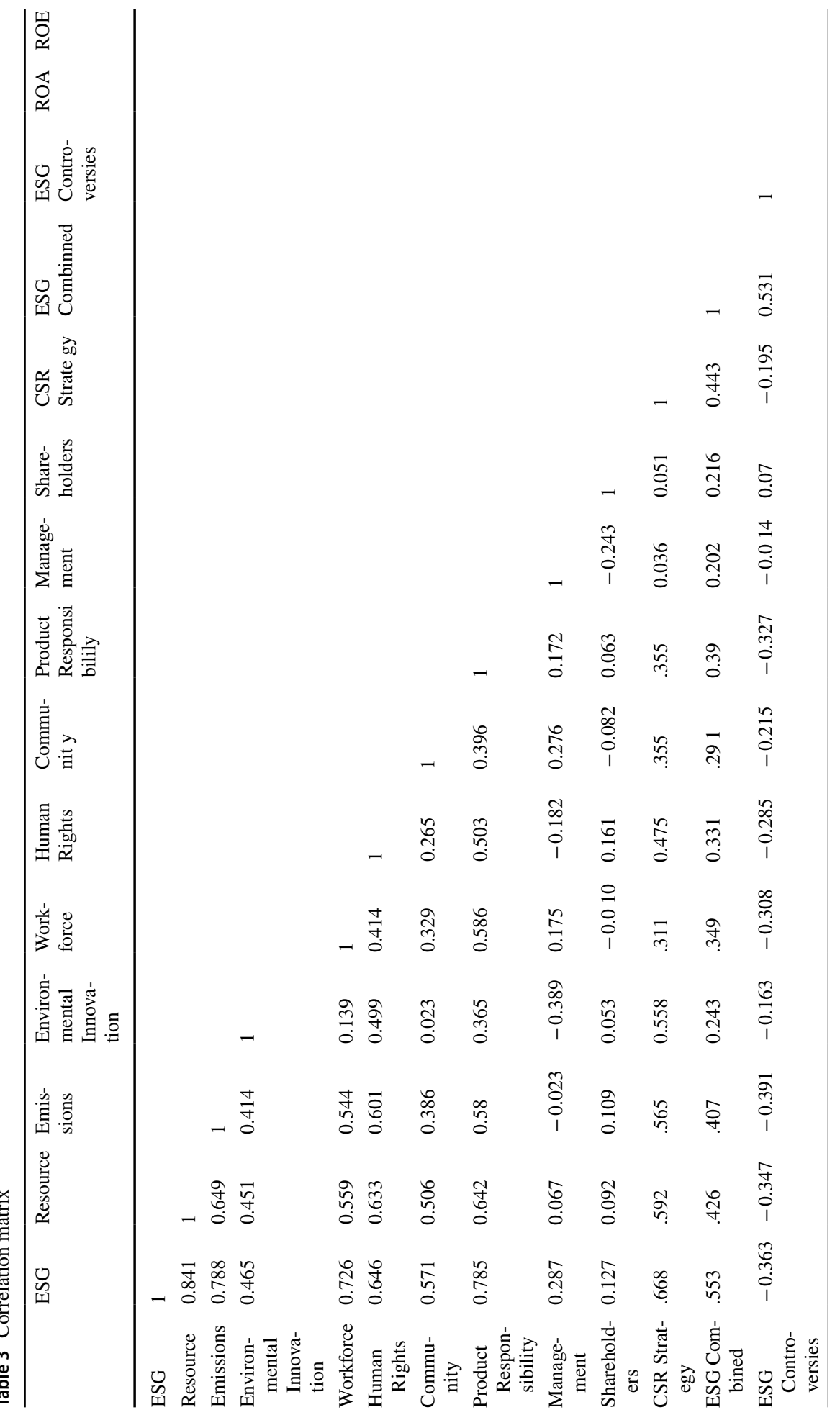




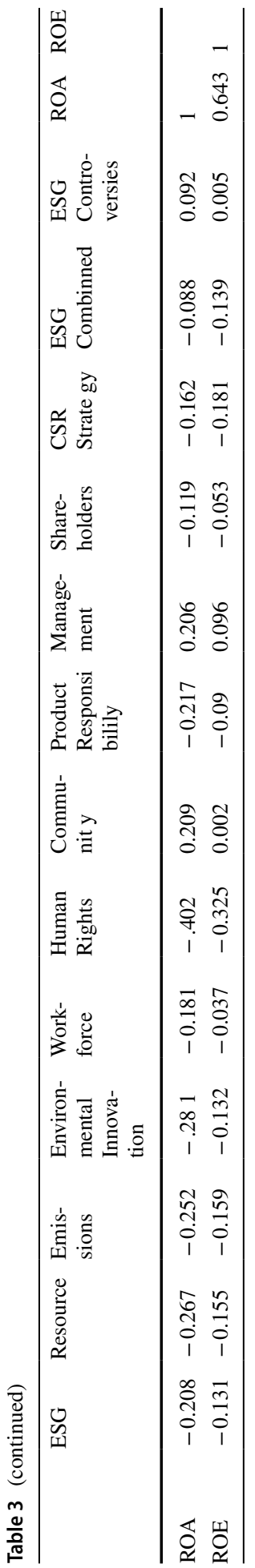


data for the years of 2014 to 2018 were observed. The path coefficients can represent the standardized regression weights and the PLS analysis results are discussed in the below section.

\subsubsection{Indicator reliability}

We have checked the reliability of data to check for its appropriateness. To analyze the relation between the latent variable and the indicators of model, we have observed the values for outer loadings through PLS method. The square of the outer loading values can provide measures of indicator reliability. The indicator reliability should be greater than 0.5 (threshold level) (Yang \& Green, 2010). In the case of our samples, the indicator reliability values of latent variables are lying in the ranges of 0.4 to 0.7 . In the reliability test, problematic indicators are removed, if their exclusion from the PLS model leads to an improvement in the average variance extracted (AVE). The composite reliability of items should be above 0.5 (threshold) (Yang \& Green, 2010). In our case for the latent variables considered, community score, management score and shareholders scores shows lesser values than 0.4. The outer loadings and the AVE measures, as observed for the model are shown in Table 4.

\subsubsection{Convergent validity}

To check the model's ability to describe the indicator's variance, convergent validity is checked through the AVE values. Fornell and Larcker (1981) suggested an AVE threshold value of 0.5 as an acceptable measure of convergent validity. In our sample, the variables of environment, social and governance have AVE values $0.668,0.567$ and 0.335 , respectively. We can see that the AVE values are satisfactory for the environmental and social factors, and in the case of governance, it is indicating a low convergent validity. This can be due to the small data set considered for the study.

\subsubsection{Coefficient of determination}

The model has been evaluated to analyze the coefficient of determination ( $\mathrm{R}$ square). In our research, ROA, ROE, ESG scores, ESG controversies scores, and ESG combined scores

Table 4 Measures of outer loadings, reliability, composite reliability, and AVE

\begin{tabular}{|c|c|c|c|c|c|}
\hline Latent variables & Indicators & Outer loadings & Indicator reliability & $\begin{array}{l}\text { Composite } \\
\text { reliability }\end{array}$ & AVE \\
\hline \multirow[t]{3}{*}{ Environment } & Emission & 0.876 & 0.767376 & 0.856 & 0.668 \\
\hline & Environmental Innovation & 0.665 & 0.442225 & & \\
\hline & Resource & 0.892 & 0.795664 & & \\
\hline \multirow[t]{4}{*}{ Social } & Community & 0.623 & 0.388129 & 0.838 & 0.567 \\
\hline & Human Rights & 0.724 & 0.524176 & & \\
\hline & Product Responsibility & 0.852 & 0.725904 & & \\
\hline & Workforce & 0.793 & 0.628849 & & \\
\hline \multirow[t]{3}{*}{ Governance } & CSR Strategy & 0.92 & 0.8464 & 0.516 & 0.335 \\
\hline & Management & 0.355 & 0.126025 & & \\
\hline & Shareholders & 0.184 & 0.033856 & & \\
\hline
\end{tabular}


Table 5 R square matrix

\begin{tabular}{lll}
\hline Indicators & R Square & R Square adjusted \\
\hline ESG combined & 0.322 & 0.305 \\
ESG controversies & 0.175 & 0.154 \\
ESG score & 0.958 & 0.957 \\
ROA & 0.046 & 0.022 \\
ROE & 0.031 & 0.007 \\
\hline
\end{tabular}

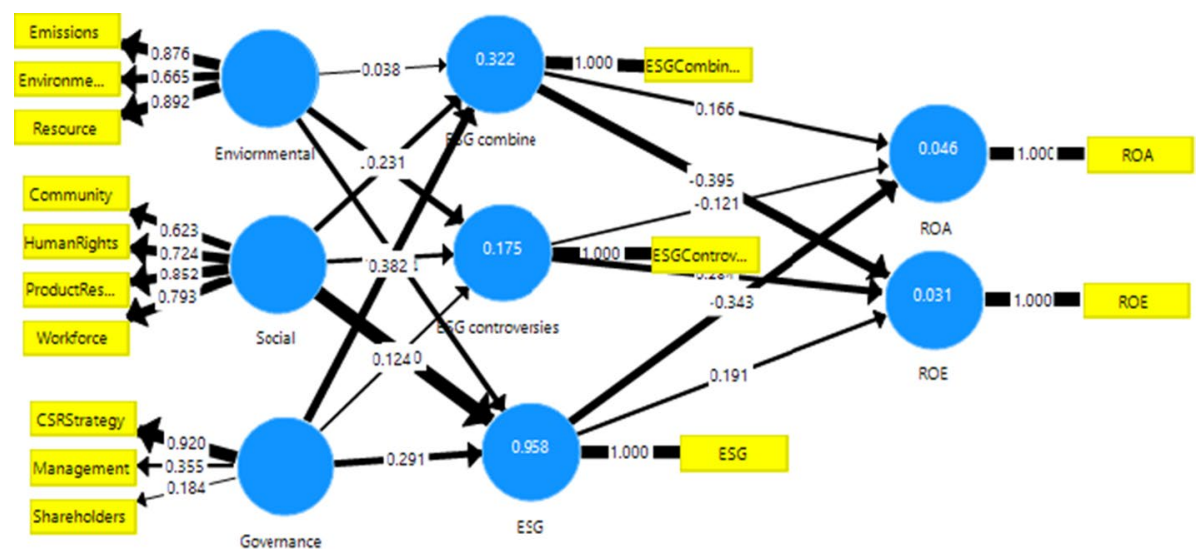

Fig. 2 PLS model and results

are the latent variables considered. From PLS path model, the overall (R square) found to be acceptable. The coefficient of determination can vary from the minimal value 0.25 to 0.5 and then to 0.7 , to describing a weak, moderate and strong predictable variance level (Hair et al., 2013). The R square and the adjusted R square measures are shown in Table 5. We use a small sample, and hence, the reliability measures appear low. This is a pilot study and this needs to be extended further to understand the exact effects of the ESG scores on financial performances of firms.

\subsubsection{Residuals and path coefficients}

The residuals matrices are constructed showing the residuals of each relationship. We have also conducted a goodness of fit analysis for a linear model. In smart PLS, the connections between builds can be observed using their path coefficients and the related measurements by means of the bootstrapping technique. The constructed path model is shown in Fig. 2 and the path coefficients and their significance on bootstrapping is indicated in Table 6. The $t$ statistics and $p$ values are used to observe the significance of the relations representing the path. We conduct $t$-test with a significance level of 0.05 and if the $t$ statistics in the path coefficient matrix is greater than 1.96, we conclude that the path is relevant and significant. Path coefficients considering many relations are not appearing significant (except marked in red color), as we consider only a pilot study in the Indian context with few firms of about 25 only. The study can be extended further to evaluate the hypothesis using more 
firms and by setting different control variables for study. From the path coefficients shown in Table 6, we can infer that the ESG scores, ESG combined scores and ESG controversies scores may not have significant effects on the financial performances of the firms, measured by ROA and ROE (see first six rows in Table 6). The results are not exhaustive as the results are based on a pilot study and the reliability indicators are low.

\subsection{Hypothesis testing}

In this study, we have observed the result of model fit of our sample size of 25 Indian companies. The datasets were observed from the Thomson Reuters and is extracted from the Bloomberg terminal database. The hypotheses were tested using $t$-tests and level of significance was taken as 0.05 . To test the hypotheses of this research, we employ a bootstrapping using the smart PLS 3 software and have calculated the $p$ value and compared those with the alpha value. The hypotheses were tested for various components representing the relationships among latent variables. The detailed results of hypotheses testing are shown in Table 7. We have examined all hypothesis test results and out of them many hypothesis were not supported (except marked in red color) based on the observed sample size. As shown in Table 7, Hypothesis 1a, Hypothesis 2a, Hypothesis 2b, Hypothesis 2c, and Hypothesis $3 \mathrm{a}$ are having acceptable $\mathrm{t}$ values. So all of these hypothesis are supported and the rest all hypotheses are not supported. The study can be extended to more companies to generalize the conclusions of the same. As this study is as a pilot study in this direction with limited number of firms under consideration, we possibly do not get enough evidence to support the financial gains of a firm, considering their sustainability performances. The hypotheses need to be tested for a large data of firms for the generalizability of the findings and to improve the reliability of the results. This is a stated limitation of the study.

\section{Conclusions and scope of future works}

We investigate the association between environmental, social, and governance practices of firms and their financial performances in the context of Indian firms. This investigation is a pilot study to explore the binding relationships. Utilizing information from the Thomson Reuters ESG and balance sheet of firm's reported data in the Indian context; we examine the sustainable supply chain practices. Here, we observe no significant connection between the joint execution of environmental, social, and governance practices and the financial performances of Indian firms, which are measured on basis of ROA and ROE. As we can see from the year-wise analysis that ESG benefit cannot occur in short-term, but it may take some time to create its benefits for firms and to show positive reflections in their financial performances. This is also another limitation of the study considering the data.

Supply chains become increasingly complex, as it connects the corporate exercises with the natural and social effects. It is assumed that the companies attempt SSCM activities can achieve benefits in their competitive performances and the same was evaluated in this study in the context of a developing economy. Specialists can use these binding relations to build up measurement models and to help firms to comprehend these effects. This can be a possible direction of future work. We have conducted the study in the Indian context and observed the data of about 25 firms. Hence, this can be considered as a pilot study in this direction and the same can be extended to several firms in the Indian context or to firms 


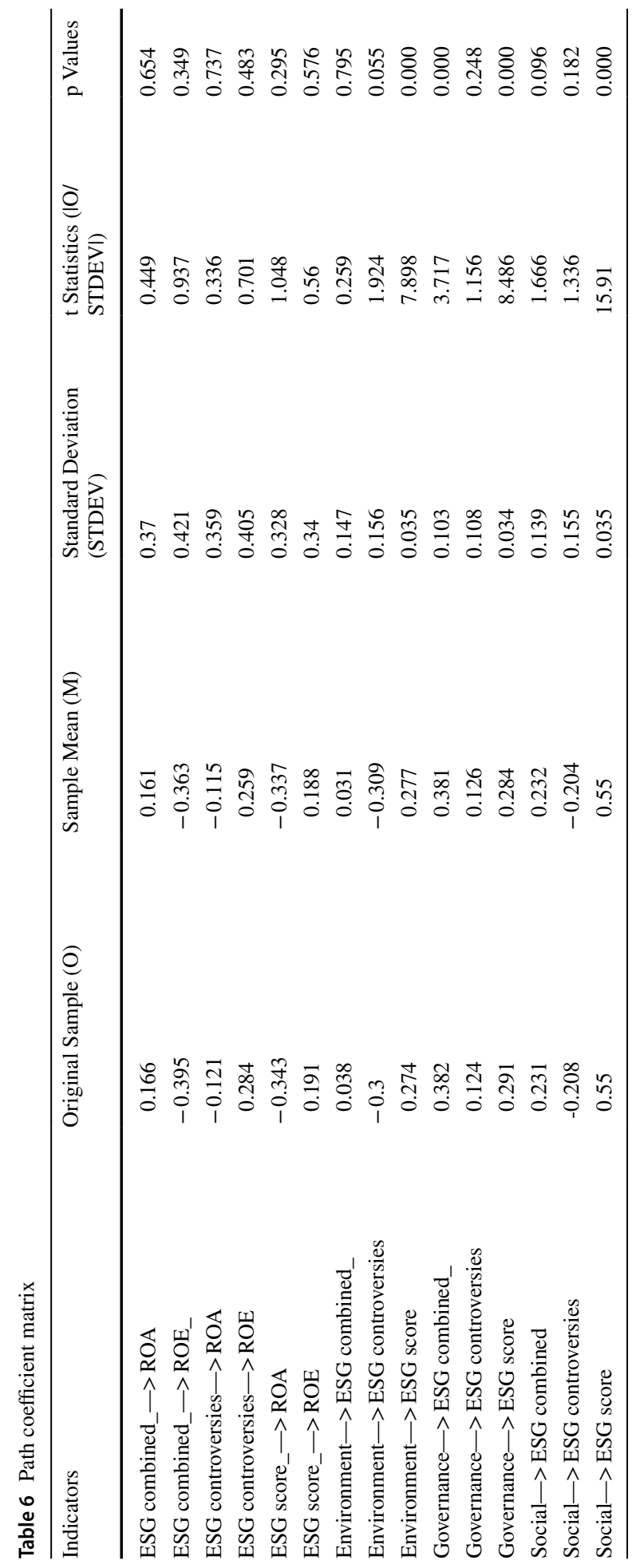




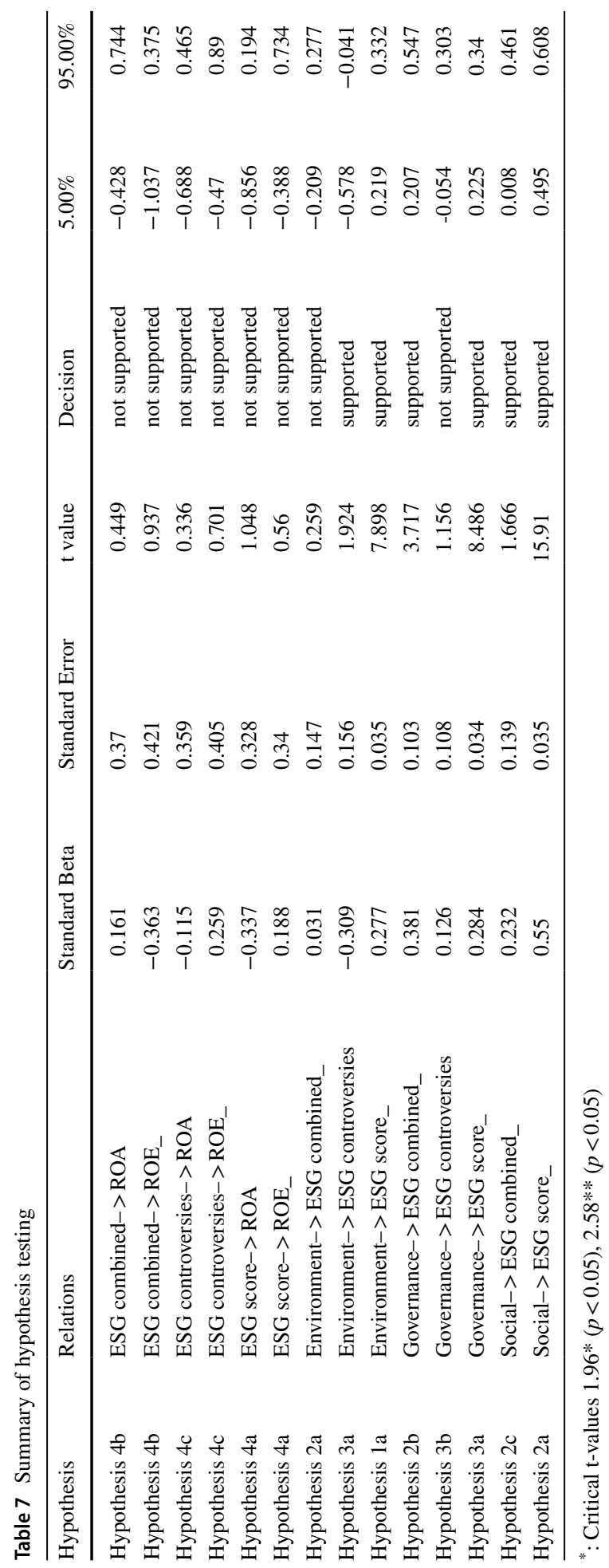


operating in developing economies, as well. This will help us to generalize the conclusions of the same.

This is another possible direction for future work. Also, the data of Thomson Reuters include those firms that are major players in the Indian business and can afford to have well-established practices in the environmental, social, and governance directions. SMEs in the Indian context were not incorporated in the study due to lack of ESG data. Primary data can be collected for this and the effects of ESG indicators over financial performances in SMEs can be studied. This appears as a limitation and a potential scope of future research in this area. The study can be further extended in the direction as a comparative study among different firms operating in various developing economies, so that the similarities and differences, while considering the environmental and social factors and the financial performances of these firms can be studied.

As already mentioned; this study considers a small data of established firms in the Indian context, who consider environmental, social, and governance performances well and are consistently rated by Thomson Reuters for ESG performances. The results of the study cannot be generalized for all firms, as the considered data size is small. But the results can throw insights into the direction that the implementation of environmental, social and governance need not always necessitate financial benefits for the firm. Also, the results points toward the critics approach to ecological modernization theory. This can be an interesting direction for future work, as researchers can explore more on ecological modernization theory and the economic benefits of firms, while considering environmental and social factors into practice. Also, the critics approach to ecological modernization theory can be studied based on a large data and the findings of the study can be validated or generalized. More details regarding the theoretical and practical implication of the study are discussed in the next section.

\section{Implications of the study}

The study points to several theoretical and managerial implications. Considering the present situation of COVID-19, the problem is more relevant, as for managers it is important to understand whether the environmental, social, and governance performances of organizations can contribute to financial gains of firms. The theoretical implications of the study are in the direction focusing on ecological modernization theory. The very theory discusses on the economic benefits of environmentalism. Based on the theory, we assume that there may be a positive association among the environmental, social, and governance (ESG) scores and financial performances of firms. The positive association was not evidenced from the data of 25 Indian firms taken for analysis. Although the results were not conclusive, we observe that the environmental, social, and governance performances need not always result in financial benefits, particularly with developing economies. The results have to be validated with large datasets from developing firms. Thus, practitioners may be more interested in increasing the long-term profits or sustainable competitive advantages of firms. Hence, the assumption that the sustainability performances of firms can always lead to their financial advantages may not be always true. This is an important finding for managers to consider environmental, social, and governance performances on a non-profit making motive.

These findings agree with the critics of ecological modernization theory that it fails to protect environment. Adding to it, critics argue that the theory cannot deal anything with 
the capitalist economic mode of production. Having profit motive in mind, while considering the environmental protection can certainly lead to environmental degradation, as per the critics of the theory. The critics of the theory points that it is form of green-washing and suggests that technological advances alone cannot achieve resource conservations or environmental protection; especially, if left to self-regulation practices in business. Hence, according to the findings of the study, it is not mandatory that environmental or social considerations in business can always results in financial gain. The results also suggest that good governance practices may focus on sustainable development, rather than short-term financial benefits of firms.

Acknowledgements The authors sincerely thank the Editor in Chief Prof. Luc Hens and the two unknown reviewers for their constructive comments for improving the manuscript.

\section{References}

Albitar, K., Hussainey, K., Kolade, N., \& Gerged, A. M. (2020). ESG disclosure and firm performance before and after IR. International Journal of Accounting \& Information Management. https://doi.org/ 10.1108/IJAIM-09-2019-0108

Balaji, R. (2010). Business ethics for micro finance institutions. Prabandhan Indian Journal of Management., 3(6), 39-47.

Balatbat, M., Siew, R., \& Carmichael, D. (2012). ESG scores and its influence on firm performance: Australian evidence. Australian School of Business School of Accounting, School of Accounting Seminar Series Semester (pp. 1-30). Australia: University of New South Wales, India.

Broadstock, D. C., Chan, K., Cheng, L. T., \& Wang, X. (2020). The role of ESG performance during times of financial crisis: Evidence from COVID-19 in China. Finance research letters, 101716.

Büyüközkan, G., \& Berkol, Ç. (2011). Designing a sustainable supply chain using an integrated analytic network process and goal programming approach in quality function deployment. Expert Systems with Applications, 38(11), 13731-13748.

Chowdhury, P., Paul, S. K., Kaisar, S., \& Moktadir, M. A. (2021). COVID-19 pandemic related supply chain studies: A systematic review. Transportation Research Part E: Logistics and Transportation Review, 102271.

Cramer, R. D. (1993). Partial least squares (PLS): Its strengths and limitations. Perspectives in Drug Discovery and Design, 1(2), 269-278.

Dorfleitner, G., Kreuzer, C., \& Sparrer, C. (2020). ESG controversies and controversial ESG: About silent saints and small sinners. Journal of Asset Management, 21(5), 393-412.

Dubey, R., Gunasekaran, A., Papadopoulos, T., Childe, S. J., Shibin, K. T., \& Wamba, S. F. (2017). Sustainable supply chain management: Framework and further research directions. Journal of Cleaner Production, 142, 1119-1130.

Esfahbodi, A., Zhang, Y., \& Watson, G. (2016). Sustainable supply chain management in emerging economies: Trade-offs between environmental and cost performance. International Journal of Production Economics, 181, 350-366.

Feng, M., Yu, W., Wang, X., Wong, C. Y., Xu, M., \& Xiao, Z. (2018). Green supply chain management and financial performance: The mediating roles of operational and environmental performance. Business Strategy and the Environment, 27(7), 811-824.

Folger-Laronde, Z., Pashang, S., Feor, L., \& ElAlfy, A. (2020). ESG ratings and financial performance of exchange-traded funds during the COVID-19 pandemic. Journal of Sustainable Finance \& Investment. https://doi.org/10.1080/20430795.2020.1782814

Fornell, C., \& Larcker, D. F. (1981). Evaluating structural equation models with unobservable variables and measurement error. Journal of Marketing Research, 18(1), 39-50.

Gandhi, N. S., Thanki, S. J., \& Thakkar, J. J. (2018). Ranking of drivers for integrated lean-green manufacturing for Indian manufacturing SMEs. Journal of Cleaner Production, 171, 675-689.

Garcia, A. S., \& Orsato, R. J. (2020). Testing the institutional difference hypothesis: A study about environmental, social, governance, and financial performance. Business Strategy and the Environment, 29(8), 3261-3272. 
García, F., González-Bueno, J., Guijarro, F., \& Oliver, J. (2020). Forecasting the environmental, social, and governance rating of firms by using corporate financial performance variables: A rough set approach. Sustainability, 12(8), 3324.

Garg, P. (2015). Impact of sustainability reporting on firm performance of companies in India. International Journal of Marketing and Business Communication, 4(3), 38-45.

Gopal, P. R. C., \& Thakkar, J. (2016). Sustainable supply chain practices: An empirical investigation on Indian automobile industry. Production Planning \& Control, 27(1), 49-64.

Hair, J. F., Ringle, C. M., \& Sarstedt, M. (2013). Partial least squares structural equation modeling: Rigorous applications, better results and higher acceptance. Long Range Planning, 46(1-2), 1-12.

Hong, J., Zhang, Y., \& Ding, M. (2018). Sustainable supply chain management practices, supply chain dynamic capabilities, and enterprise performance. Journal of Cleaner Production, 172, 3508-3519.

Jamali, D., \& Karam, C. (2018). Corporate social responsibility in developing countries as an emerging field of study. International Journal of Management Reviews, 20(1), 32-61.

Jayaram, J., Vickery, S., \& Droge, C. (2008). Relationship building, lean strategy and firm performance: An exploratory study in the automotive supplier industry. International Journal of Production Research, 46(20), 5633-5649.

Lee, D., \& Schniederjans, M. J. (2017). How corporate social responsibility commitment influences sustainable supply chain management performance within the social capital framework: A propositional framework. International Journal of Corporate Strategy and Social Responsibility, 1(3), 208-233.

Lins, K. V., Servaes, H., \& Tamayo, A. (2017). Social capital, trust, and firm performance: The value of corporate social responsibility during the financial crisis. The Journal of Finance, 72(4), 1785-1824.

Mann, B. J. S., \& Kaur, H. (2020). Sustainable supply chain activities and financial performance: An Indian experience. Vision, 24(1), 60-69.

Mathivathanan, D., Govindan, K., \& Haq, A. N. (2017). Exploring the impact of dynamic capabilities on sustainable supply chain firm's performance using Grey-Analytical Hierarchy Process. Journal of Cleaner Production, 147, 637-653.

Miroshnychenko, I., Barontini, R., \& Testa, F. (2017). Green practices and financial performance: A global outlook. Journal of Cleaner Production, 147, 340-351.

Mol, A. P., \& Spaargaren, G. (2000). Ecological modernisation theory in debate: A review. Environmental Politics, 9(1), 17-49.

Narimissa, O., Kangarani-Farahani, A., \& Molla-Alizadeh-Zavardehi, S. (2020a). Evaluation of sustainable supply chain management performance: Dimensions and aspects. Sustainable Development, $28(1), 1-12$.

Narimissa, O., Kangarani-Farahani, A., \& Molla-Alizadeh-Zavardehi, S. (2020b). Evaluation of sustainable supply chain management performance: Indicators. Sustainable Development, 28(1), 118-131.

Nekhili, M., Boukadhaba, A., \& Nagati, H. (2020). The ESG-financial performance relationship: Does the type of employee board representation matter? Corporate Governance: An International Review, 29, 134. https://doi.org/10.1111/corg.12345

Nirino, N., Santoro, G., Miglietta, N., \& Quaglia, R. (2021). Corporate controversies and company's financial performance: Exploring the moderating role of ESG practices. Technological Forecasting and Social Change, 162, 120341.

Ortas, E., Moneva, J. M., \& Álvarez, I. (2014). Sustainable supply chain and company performance: A global examination. Supply Chain Management: An International Journal, 19(3), 332-350.

Ouni, Z., Ben Mansour, J., \& Arfaoui, S. (2020). Board/Executive gender diversity and firm financial performance in Canada: The mediating role of environmental, social, and governance (ESG) orientation. Sustainability, 12(20), 8386.

Rajesh, R. (2020). Flexible business strategies to enhance resilience in manufacturing supply chains: An empirical study. Journal of Manufacturing Systems. https://doi.org/10.1016/j.jmsy.2020.10.010

Rajesh, R. (2021). Optimal trade-offs in decision-making for sustainability and resilience in manufacturing supply chains. Journal of Cleaner Production, 313, 127596.

Rajesh, R., Agariya, A. K., \& Rajendran, C. (2021). Predicting resilience in retailing using grey theory and moving probability based Markov models. Journal of Retailing and Consumer Services, 62, 102599.

Sybertz, J. (2017). Sustainability and effective supply chain management: A literature review of sustainable supply chain management, Sustainable supply chain research fellowship report, NYU, Stern.

Tamayo-Torres, I., Gutierrez-Gutierrez, L., \& Ruiz-Moreno, A. (2019). Boosting sustainability and financial performance: The role of supply chain controversies. International Journal of Production Research, 57(11), 3719-3734.

Tchaikovsky, Z. (2017). The Relationship Between Sustainable Supply Chain Management, Stakeholder Pressure, and Financial Performance, Doctoral dissertation, Walden University. 
Thomson Reuters ESG Scores (February, 2019), https://www.refinitiv.com/content/dam/marketing/en_us/ documents/methodology/esg-scoresmethodology.pdf

Tseng, M. L., Wu, K. J., Lim, M. K., \& Wong, W. P. (2019). Data-driven sustainable supply chain management performance: A hierarchical structure assessment under uncertainties. Journal of Cleaner Production, 227, 760-771.

Uyar, A., Kilic, M., Koseoglu, M. A., Kuzey, C., \& Karaman, A. S. (2020). The link among board characteristics, corporate social responsibility performance, and financial performance: Evidence from the hospitality and tourism industry. Tourism Management Perspectives, 35, 100714.

Wang, Z., \& Sarkis, J. (2017). Corporate social responsibility governance, outcomes, and financial performance. Journal of Cleaner Production, 162, 1607-1616.

Wolf, J. (2014). The relationship between sustainable supply chain management, stakeholder pressure and corporate sustainability performance. Journal of Business Ethics, 119(3), 317-328.

Yang, Y., \& Green, S. B. (2010). A note on structural equation modeling estimates of reliability. Structural Equation Modeling, 17(1), 66-81.

Yusuf, Y., Menhat, M. S., Abubakar, T., \& Ogbuke, N. J. (2019). Agile capabilities as necessary conditions for maximising sustainable supply chain performance: An empirical investigation. International Journal of Production Economics, 107501.

Publisher's Note Springer Nature remains neutral with regard to jurisdictional claims in published maps and institutional affiliations. 